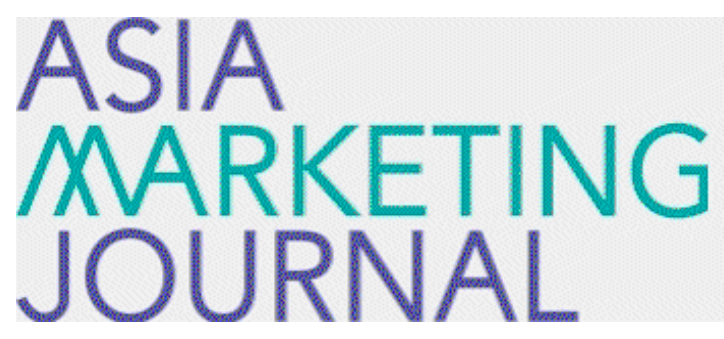

ASIA MARKETING JOURNAL

Volume 16 | Issue 3

Article 5

$10-31-2014$

\title{
Automotive telematics market segmentation based on quality expectations
}

Dayoung Kim

Donghee Kim

Jungsuk Oh

Follow this and additional works at: https://amj.kma.re.kr/journal

Part of the Marketing Commons

\section{Recommended Citation}

Kim, Dayoung; Kim, Donghee; and Oh, Jungsuk (2014) "Automotive telematics market segmentation based on quality expectations," Asia Marketing Journal: Vol. 16 : Iss. 3 , Article 5.

Available at: https://doi.org/10.15830/amj.2014.16.3.57

This Article is brought to you for free and open access by Asia Marketing Journal. It has been accepted for inclusion in Asia Marketing Journal by an authorized editor of Asia Marketing Journal. 


\title{
Automotive telematics market segmentation based on quality expectations*
}

\author{
Dayoung Kim** \\ Donghee Kim*** \\ Jungsuk $\mathrm{Oh}^{* * * * *}$
}

\begin{abstract}
This paper explores the possibility of segmentation of consumers based on their quality expectations toward the automotive telematics service. Hypotheses on utilizing consumers' expectations toward the automotive telematics service for the market segmentation and linking the segments with optimal product designs are formulated. Samples are segmented based on their perceived service quality to the service attributes from various configurations of automotive telematics service. Then, a regression analysis on the segmented groups of users is performed to check whether they have qualitatively differing evaluation on the service quality. The result indicates that the proposed segmentation is operational and differing product attributes configuration is desirable according to the characteristics of the consumer segment. Hence, according to the characteristics of each consumer segment formed based on their expectation toward the telematics service, a product differentiation strategy of the automotive telematics system can be designed and be proposed to the product line designer.
\end{abstract}

Key words: Automotive telematics, quality expectations based segmentation, service quality, product design

\section{Introduction}

Under today's ubiquitous computing environment, new services are rapidly emerging due to the convergence trend among telecommunications, broadcasting, and GPS (Global Positioning System) technologies. The development of cutting-edge information technology and the highquality ubiquitous services have raised customers'

\footnotetext{
* This Study was supported by the Institute of Management Research at Seoul National University.

** Business School, Seoul National University

*** Business School, Seoul National University

**** Business School, Seoul National University(joh@snu.ac.kr)
} 
expectation toward automotive telematics system. As of early 2013, more than 30 vehicle manufacturers have launched telematics services (a 50\% growth since 2010) and additional 9 vehicle manufacturers are planning to launch new services over the coming year. It is predicted that by 2015, over 30 million new cars will be fitted with some type of connectivity box and world commercial vehicle telematics market will reach 17.3 billion USD by the year 2017 (Global Industry Analysts, 2012). Despite the rapid increase in the size and the importance of the automotive telematics market, major players have yet to better understand characteristics of the market and customers. For example, despite many new-vehicle owners saying their navigation system is better than their previous system, navigation system satisfaction has declined from 2011 substantially (J.D. Power and Associates, 2012).

With the increased diversification of vehicle models now offered on the market, the usual market 'segments' defined according to engine size no longer apply. The vast availability of new technological alternatives offers automobile manufacturers a variety of possibilities to configure unique combinations and to create quite distinctive cars (Fornengo, 1988). Considering its importance, automotive telematics system design is a well-deserving investment for today's automobile makers to differentiate themselves from others.

This study provides an initial attempt to ap- ply market segmentation approach based on service quality expectation to automobile telematics market and to align the characteristics target consumers' needs with the telematics system design. This paper proceeds with the following two steps. First, we assume that consumers have heterogeneous expectation on the service specification of automobile telematics, and one can segment the consumer pool according to the expectation level on the service provided by the device. The groups of customers with homogeneous expectation on the service attributes of automotive telematics are identified using factor analysis and cluster analysis on the data from one of the major telematics manufacturer and service provider in Korea.

Second, the optimal product (hardware) design for each group to fit the unique needs of each segment is offered. This is the process in which the product (hardware) design is aligned with the service offerings. Specific research hypotheses for this purpose are: when customers in a segment with homogeneous quality response choose their automotive telematics system, they exhibit homogeneous satisfaction patterns regarding the hardware specification that are distinct from those of other segments. We show that the product specification of the automotive telematics can be aligned with customer segments with heterogeneous attitudes toward the service aspects of telematics. 


\section{Literature review}

\subsection{Automotive telematics}

Telematics originally referred to the convergence of telecommunications and information processing. The term later evolved to refer to automation in automobiles, such as the invention of the emergency warning system for automotives (Wikipedia). Automotive telematics services constitute one of the major areas of innovation for the future of the automotive industry (Lenfle \& Midler, 2003), and thus, appear in many research papers particularly in the field of transportation and information science. For example, Chen \& Chen (2009) proposed an adoption decision model of automotive telematics service utilizing technology acceptance model (TAM), the theory of planned behavior (TPB), and combined TAM-TPB model (C-TAM-TPB).

Since the automotive telematics system is not just a device, but an integrated service that facilitates automobile life, and rapid technological changes introduce new functionalities affecting both the product and the service, it is important to understand the telematics system from an integrative perspective that encompass both the product and the service characteristics of it. As such, traditional design models are unsuitable for automotive telematics services (Lenfle \& Midler 2003) and only a few studies such as Williams (2007) and Lenfle \& Midler
(2009) focused on the fact that automotive telematics system is the combination of the service and the product (the hardware device.) Particularly, the service aspect is more important in terms of the impact on customers' satisfaction whereas the product aspect is more relevant to the operational scheme of the manufacturer.

\subsection{Segmentation}

Segmentation is the process of partitioning the market into groups of potential customers with similar needs and/or characteristics who are likely to exhibit similar purchase behavior (Weinstein, 1994). One of the main purposes of segmenting a market is to help researchers identify variables that can differentiate various segments in the mass market (Woo, 1998). Segmentation studies commonly involve the determination of the segments followed by the identification of the segment profile on the respondents' other characteristics (Wind, 1978).

Objective and general variables such as demographic, socio-economic and geographical variables have been popular choices for market segmentation purpose due to their simplicity and availability (Haley, 1968; Frank et al, 1972). However, segmentation results based on general objective characteristics are less than optimum due to their inadequate performance (Haley, 1968). Alternative methods based on subjective variables have been explored ever since. Benefits sought by consumers have received increasing 
attention due to their causal nature (i.e., benefits sought by consumers determine their behavior much more accurately than do demographic variables) (Haley, 1968). On the other hand, this benefit segmentation method has inherent implementation hurdles such as data requirement, accessibility and identifiableness (Moriarty, 1986). Such hurdles are even more salient in service industries and high-tech and/ or innovation product markets in which the market is dynamic, there is a high uncertainty for consumer and after-sales support is important (Pitt et al., 1996).

\subsection{Service quality and segmentation approach using consumer expectation}

There has been another segmentation approach based on a subjective variable of consumers' expectations. It has long been established that satisfaction with services is related to confirmation or disconfirmation of quality expectations (Gronroos, 1984; Parasuraman et al., 1988; Zeithaml et al., 1993). Ever since, the role of quality expectation in E-business market dynamics has been emphasized extensively (Loiacono et al., 2002; Parasuraman et al., 2005; Zeithaml et al., 2002; Yoo \& Donthu, 2001; Yang \& Fang, 2000; Rust \& Lemon, 2001).

Based on the theory of role of quality expectations on customer satisfaction, there have been studies that implemented the segmentation method based on the consumer's service quality expectation. Webster (1989) explored the segmentation by service marketers on the basis of service quality expectations. Thompson \& Kaminski (1993) determined whether consumerbased variables such as activities, interests and opinions could be used to segment markets based on service quality expectations and discussed the managerial significance to the healthcare market. Gagliano et al. (1994) examined the differences between consumers' expectations and perceptions of service quality they received when shopping apparel specialty stores. Pitt et al. (1996) successfully applied quality expectation based segmentation to business-to-business, high technology industry such as software industry. Diaz-Martin, et al. (2000) showed that consumers' quality expectations can be used to segment the market in the tourism industry. They clustered customers based on the attributes of the quality expectation on tourism market and conducted Chow test to validate that each segment has different quality expectation which in turn, affects the satisfaction level. Dean (2004) investigated the impact of quality expectation on customer orientation in call center service context. Agarwal et al. (2010) addressed global market segmentation strategy in banking service industry using segmentation approach based on quality expectation.

In online service context, the importance of quality expectation has been studied. Driver et al. (2001) revealed that the impacts of service quality evaluations differ according to the type 
of customers. Since classifying the customers based on their tendency is important, they assumed that growth of the Internet user population will diversify the composition of customers with respect to quality expectations on online shops. Moreover, they showed that based on the quality expectation diversity, segmentation can be an effective marketing tool for setting the target customers. Seltsikas \& O'keefe (2010) emphasized the role of 'trust' in electronic identity management system in linking expectations and outcomes of the system. In Otim \& Grover (2006), customer loyalty in web-based services is influenced by pre-purchase services such as product search, evaluation and aesthetics aspects, which are implied to affect quality $\mathrm{ex}^{-}$ pectations of consumers. Nevertheless, it is hard to find academic research applying quality expectation based approach to segmentation to automotive telematics or similar network-based services markets.

\subsection{Product design}

Green et al. (1981) provided an overview of literatures on general approach to product design optimization. Although most of the works on new product development are focused on the physical goods markets, there have been some works on markets characterized by productservice combination. Lenfle \& Midler (2009) defined services that are closely associated with goods and products as Product-Related Services
(PRS). They studied the management of the final phases of the design process of an innovative product-related service. On the other hand, Bloch (1995) focused on the product design to better investigate the role of physical form or design of a product for the market success. Here, the form or design of a product may contribute to its success not only because it attracts consumers' attention, but also because it serves as a mean of communication with consumers.

\section{Model and research design}

\subsection{Research model}

Among segmentation approaches utilizing various information including demographic variables, benefits sought and quality expectations, quality expectations have been deemed suitable for application to the automotive telematics market for the following reasons. First, due to the lack of adequacy of segmentation efforts along the demographic variables for our data set, we have ruled out the possibility of adopting segmentation using demographic variables. Particularly, we have tested whether the respondents with homogeneous demographic characteristics have homogenous expectations on service aspects or product specifications of telematics, and failed to find significant evidences. Second, we also ruled out the benefit segmentation method due 
to the aforementioned implementation difficulties associated with it, especially for service and/or high-tech markets. Third, as illustrated, from the literature review result, by the fact that most of the applications of segmentation approach based on quality expectation have been concentrated on service and online industries, and also judging from the characteristics of the automotive telematics service, which exhibits many traits of online and service markets, the quality expectation approach has been deemed suitable for the segmentation purpose.

Hypotheses on utilizing consumers' expectations toward the automotive telematics service for the market segmentation and linking the segments with optimal product designs are formulated. Then, through consumer segmentation based on quality expectation, various patterns of emphases on service attributes are matched with the product design configurations.

The following two hypotheses pertain to the task of validating quality expectation approach to segmentation for automotive telematics market.

H1: Consumers in the automotive telematics market have heterogeneous expectation on service quality.

H2: Customers belonging to different segments put statistically different level of importance toward service attributes of telematics service.

In general, telematics service users make their purchasing decisions based largely on the product factors such as hardware design, product specification and price due to the fact that it is difficult to experience all the services of the telematics system prior to the purchase. In addition, the specification of the product (hardware) design and service design of telematics is mostly predetermined before the launch of the product and the service. Consequently, it would be more relevant for suppliers if the product hardware design side of information is accompanied by the information on consumers' service preferences.

In order to examine the influence of the product design on the customer satisfaction of different segments, the following hypothesis is proposed.

H3: The customer segments formed along the service quality expectation will put different importance on the product design (specification), which influences their satisfaction.

In order to test these hypotheses, methodologies utilized in Diaz-Martin et al. (2000) were employed.

\subsection{Sample and data collection}

Data in this study was collected during a customer service management project with one of the major telematics system (including the product and the service) provider in South Korea (which is referred to as IT-Car due to confidentiality). Before the actual customer survey, 
multiple interview sessions with the IT-Car employees and experts were undertaken in order to identify and to analyze the service attributes of the automotive telematics system. First, generic service attributes were extracted from the literatures on SERVQUAL model (Carman 1990) to make sure the most widely used aspects of service quality in academia are included in our survey. Second, thorough brain storming sessions with in-house experts were conducted to uncover specific service attributes relevant to automotive telematics systems. As a result, a pool of 18 items of service quality determinants in automotive telematics systems was established. During the process, the concept of 'product', which mainly designates hardware aspect of the telematics system, was distinguished from the concept of 'service', which covers non-material provision of assistance to customers. The resulting service attributes were refined through an additional step of executive interview as indicated in Table 1.

The value of the Cronbach-alpha coefficient was greater than 0.85 . The use of these 18 attributes to evaluate customers' service expectation is considered reliable. The survey questionnaire on the quality expectation level on service attributes was based on a seven-point scale. In addition, overall satisfaction level toward the automotive telematics systems was asked. The survey questionnaire was administered to the telematics system users of the IT-Car and total of 412 valid responses were used for the final analysis.

One limitation of our study is the lack of role of main demographics variables such as gender and age. Our data consist of mainly male sample ( $82 \%$ of respondents), and the age distribution is rather focused $(64 \%$ of the respondents in their 30-40s). In addition, although we have tried to include demographic variables as control variables, the regression results were not significantly affected.

\section{Analysis and interpretation of results}

\subsection{Factor analysis}

During the factor analysis, higher dimensions of service attributes are extracted to avoid possible duplications and multicollinearity, which also resulted in more meaningful and interpretable outcomes. SPSS 16.0 was used for exploratory factor analysis. 18 service quality items were condensed into several meaningful dimensions for the cluster analysis for the purpose of segmenting customers based on their expectation scores. Although the use of factorcluster technique is questioned by some re- $^{-}$ searchers (Arabie \& Hubert, 1994), it is the most popular choice for the purpose of market segmentation in many disciplines (Mitchell, 1994; Woo, 1998; Loker \& Perdue, 1992; Rao \& 
$\langle$ Table 1〉 Service descriptions

\begin{tabular}{|c|c|}
\hline no & Service \\
\hline 1 & $\begin{array}{l}\text { [ARS service] } \\
\text { Car IT system equipped with voice recognition terminal offers all the available services through voice search. }\end{array}$ \\
\hline 2 & $\begin{array}{l}\text { [Counseling service] } \\
\text { Counselor offers various services including navigation; search for nearby famous restaurant, and stock market } \\
\text { update through phone calls. }\end{array}$ \\
\hline 3 & $\begin{array}{l}\text { [Management of private information service] } \\
\text { Once having registered private information such as one's schedule in Car IT web homepage, a driver is available } \\
\text { for such information by synchronizing it with Car IT system. }\end{array}$ \\
\hline 4 & $\begin{array}{l}\text { [Daily information service] } \\
\text { Core daily information including stock market, weather, and traffic information is provided through Car IT system. }\end{array}$ \\
\hline 5 & $\begin{array}{l}\text { [Restaurant/Travel information service] } \\
\text { Local famous restaurants, accommodations, travel information is provided inside car through Car IT system. }\end{array}$ \\
\hline 6 & $\begin{array}{l}\text { [Mobile phone service] } \\
\text { Safe phone calls while at the wheel. }\end{array}$ \\
\hline 7 & $\begin{array}{l}\text { [Fuel price indicator service] } \\
\text { Information about the gas station with the cheapest fuel price and the shortest way to it is provided though Car } \\
\text { IT system. }\end{array}$ \\
\hline 8 & $\begin{array}{l}\text { [Location identification service] } \\
\text { In case of forgetting the location of one's car in a complex or wide place, Car IT system tells the exact location } \\
\text { by flashing emergency lamps or horning. }\end{array}$ \\
\hline 9 & $\begin{array}{l}\text { [Consumables management service] } \\
\text { Car IT system enables an efficient management of car by informing dates for parts replacement. }\end{array}$ \\
\hline 10 & $\begin{array}{l}\text { [Location notification service] } \\
\text { Car IT system teaches the location of one's car to oneself online or to other drivers with the same Car IT system. }\end{array}$ \\
\hline 11 & $\begin{array}{l}\text { [Remote door-unlocking service] } \\
\text { In case of being locked outside, Car IT system provides remote unlocking service after identifying the caller. }\end{array}$ \\
\hline 12 & $\begin{array}{l}\text { [Tele-diagnosis service] } \\
\text { In case of alarm flashing on the gauge due to faults in car operations, Car IT system automatically diagnoses the } \\
\text { problem and links the driver with a counselor. }\end{array}$ \\
\hline 13 & $\begin{array}{l}\text { [Theft tracking service] } \\
\text { In case of car theft, Car IT system provides prompt identification of car location with assistance from police. }\end{array}$ \\
\hline 14 & $\begin{array}{l}\text { [Automatic notice service of air bag inflation] } \\
\text { In case of car accident in which air bag inflates and passengers are unconscious, Car IT system automatically } \\
\text { notices monitoring agents of the accident, who makes a call to car passengers to bring back their consciousness } \\
\text { and cope with the situation. }\end{array}$ \\
\hline 15 & $\begin{array}{l}\text { [Theft alarming service] } \\
\text { In case of car theft alarming taking off, text message is automatically sent to the phone of the car owner. }\end{array}$ \\
\hline 16 & $\begin{array}{l}\text { [SOS emergency service] } \\
\text { In case of emergency, putting on SOS button will be automatically accompanied with prompt assistance from } \\
\text { police, hospital, and insurance companies through Car IT system. }\end{array}$ \\
\hline 17 & $\begin{array}{l}\text { [Short-cut navigation service] } \\
\text { Smart navigation which looks for the best route considering distance from starting point to destination, traffic } \\
\text { congestion, and the other traffic information. }\end{array}$ \\
\hline 18 & $\begin{array}{l}\text { [Fuel saving navigation service] } \\
\text { Advanced navigation which looks for the best route considering fuel price and efficiency as well as traffic } \\
\text { information. }\end{array}$ \\
\hline
\end{tabular}


Wang, 1995; Athanassopoulos, 2000; Furrer et al., 2000; Bernués, 2003; Okazaki, 2006; Wu, 2006: Verbeke et al., 2007; Dimitriadis, 2011; Liu et al., 2012; ). The application of a principal component factor analysis with VARIMAX rotation produced a solution of four factors with eigenvalues greater than one.

As a result of extracting the factors with eigenvalues greater than 1 , the service attributes were classified into four different dimensions. The factors representing the sub-items were renamed as Personally customized IT service for Component 1 , which covers the service items 12-18: Convenient management for Component 2, which covers the items 7-11: Safety service for Component 3, which covers the items 1-4; and Intelligent navigation for Component 4, which covers the items 5-6. This result shows that customers perceive the service portfolio to be part of a system consisting of four conceptual dimensions.

$\mathrm{KMO}$ and Bartlett's statistics were also checked for the purpose of assessing whether there are patterns of correlations in the data that indicate that factor analysis is suitable. As in Table 2, KMO value is high (close to 1 ) which indicates good suitability, and Bartlett's statistics is significant $(p<0.001)$. From these, the factor analysis is deemed suitable for the data.

\subsection{Cluster analysis}

After reducing the dimensions of service attributes into four, cluster analysis was performed to identify customer segments according to the customers' service quality expectations. Using the $\mathrm{k}$-means clustering method, three-group clustering turned out to be the most efficient.

Table 3 reveals different mean expectation scores of each cluster. We have based this on the questions asking the 'importance' of each service attribute. K-means clustering method partitions the individual observation to belong to the cluster with the nearest mean. The F-test result of Table 4 exhibits validity of the clustering result. That is, all four service dimensions were effective in segmenting customers into 3 different groups which support Hypothesis 1. Although overall expectation levels of each cluster can be described as (1) people with the highest expectation level - cluster 1

〈Table 2〉 Validity test statistics of factor analysis

* Correlation Matrix : Variables Correlated

$*$ Determinant $=5.30 \mathrm{E}-005$

KMO and Bartlett's Test

\begin{tabular}{|c|c|c|}
\hline \multicolumn{2}{|c|}{ Kaiser-Meyer-Olkin Measure of Sampling Adequacy. } & .913 \\
\hline \multirow[t]{3}{*}{ Bartlett's Test of Sphericity } & Approx. Chi-Square & $3.979 \mathrm{E} 3$ \\
\hline & Df & 153 \\
\hline & Sig. & .000 \\
\hline
\end{tabular}


$\langle$ Table 3〉 Final cluster centers

\begin{tabular}{|l|c|c|c|}
\hline \multirow{2}{*}{} & \multicolumn{3}{|c|}{ Cluster } \\
\cline { 2 - 4 } & 1 & 2 & 3 \\
\hline Convenient management & 6.45 & 4.39 & 5.25 \\
Safety service & 6.70 & 5.52 & 6.32 \\
Intelligent navigation & 6.57 & 3.87 & 5.85 \\
Personally customized IT service & 6.03 & 3.32 & 4.56 \\
\hline
\end{tabular}

$\langle$ Table 4〉 ANOVA test result

\begin{tabular}{|l|c|c|c|c|c|c|}
\hline & \multicolumn{2}{|c|}{ Cluster } & \multicolumn{2}{c|}{ Error } & \multirow{2}{*}{ F } & Sig. \\
\cline { 2 - 6 } & Mean Square & Df & Mean Square & Df & F & .462 \\
Convenient management & 118.501 & 2 & 409 & 256.770 & .000 \\
Safety service & 31.348 & 2 & .488 & 409 & 64.239 & .000 \\
Intelligent navigation & 160.463 & 2 & .566 & 409 & 283.262 & .000 \\
Personally customized IT service & 194.662 & 2 & .514 & 409 & 378.470 & .000 \\
\hline
\end{tabular}

The $\mathrm{F}$ tests should be used only for descriptive purposes because the clusters have been chosen to maximize the differences among cases in different clusters. The observed significance levels are not corrected for this and thus cannot be interpreted as tests of the hypothesis that the cluster means are equal.

(2) people with the intermediate expectation level - cluster 3 (3) people with the lowest expectation level - cluster 2, their average cluster centers were distinctively located apart. From Table 5, customers with the highest expectation level correspond to the largest portion of the sample $(45 \%)$, customers with the intermediate expectation level occupies $41 \%$ and customers with the lowest expectation level correspond to $14 \%$ of the total respondents.

On the other hand, the second hypothesis, H2, which proposed that expectation-based segmentation will be able to discriminate segments in terms of patterns of importance placement among service dimensions, was not supported. Nevertheless, there are a few observations of practical significance. First, cluster 1, which represents the biggest portion of the entire sample, exhibited the highest overall expectation level. Considering from the fact that features of the automotive telematics product/service are still rapidly improving, such high expectations from many customers are comprehensible which can provide confidence to the suppliers of telematics systems as to the high market potential. Second, it is observed that most customers tend to expect more from the services regarding safety and theft alarming functions than from others. This tendency becomes more apparent with customers with lower expectations. From these observations, the supplier is suggested to target the low expectation segment with the system offering good safety and theft prevention features. 
〈Table 5〉 Segmented group identification

\begin{tabular}{|l|l|c|c|c|}
\hline Segment & \multicolumn{1}{|c|}{ Characteristics } & $\begin{array}{c}\text { Size of the group } \\
(\%)\end{array}$ & $\begin{array}{c}\text { Gender } \\
\text { (M/F) }\end{array}$ & $\begin{array}{c}\text { Age } \\
\text { (mean) }\end{array}$ \\
\hline Group 1 & $\begin{array}{l}\text { Cluster \#1 - shows the highest expectation level } \\
\text { toward all 4 service attributes; fairly interested } \\
\text { group of car users }\end{array}$ & $=187 / 412(45 \%)$ & $156 / 22$ & 46 \\
\hline Group 2 & $\begin{array}{l}\text { Cluster \#3 - shows the medium expectation level } \\
\text { overall; relatively expects more from safety service } \\
\text { and less from personally customized IT service }\end{array}$ & $=168 / 412(41 \%)$ & $42 / 9$ & 42 \\
\hline Group 3 & $\begin{array}{l}\text { Cluster \#2 - shows the lowest expectation level } \\
\text { overall; relatively expects more from safety service } \\
\text { and less from personally customized IT service }\end{array}$ & $=57 / 412(14 \%)$ & $142 / 16$ & 45 \\
\hline
\end{tabular}

\subsection{Alignment of product design with customer segments}

There are many markets with characteristics that products and services cannot be clearly disconnected (Edvardsson, et al., 2000). Under such environment, a product can be defined as a combination of the good and services with differing relative weights between them. Salient examples of such markets are the smart phone market and the automotive telematics market. In order to link the service aspects with physical product design by evaluating how customer segments react in different ways to the physical product aspect of telematics, the influence of the product (hardware) specification on the overall satisfaction level of each consumer segment is examined and statistically compared. Through several expert interviews with IT-Car employees, the following major product offerings are identified.
1. Product (hardware) price

2. Design (compatibility with the car interior)

3. LCD size

4. Ease of updating the map

5. Ease of understanding/using the user interface and functions

6. Multimedia technology specification (CD/ DVD, DMB, MP3, Bluetooth etc.)

Then, a regression analysis was conducted to inspect the relationship between the satisfaction of specific product offerings and customers' overall satisfaction.

As a result of the regression analysis for all the respondents and for each of the different customer segment, none of the analysis attained the statistically significant coefficient for the 'size' of the product. Due to relatively new nature of the telematics systems from the end users' perspective, they might not have enough experiences of various sizes of the system, leading to ignorance of appreciation for the product 
$\langle$ Table 6〉 Regression results

\begin{tabular}{|cl|c|c|c|}
\hline & B & SE & Beta \\
\hline 1 & (Constant) & 1.209 & .295 & $.315^{* * *}$ \\
& Price & .554 & .083 & $.094^{*}$ \\
Design & .172 & .090 & -.041 \\
Size & -.062 & .071 & $.093^{* *}$ \\
Updatemap & .130 & .066 & $.117^{* *}$ \\
Easyuse & .194 & .084 & $.216^{* * *}$ \\
Multimedia & .316 & .073 & *** significance 0.01 ** significance $0.05 *$ significance 0.1 \\
\hline
\end{tabular}

a. Dependent Variable: SATISFACTION

B: Unstandardized Coefficients, SE: Std. Error, Beta: Standardized Coefficients

〈Table 7〉 Regression results (excluding the 'product size')

\begin{tabular}{|cl|c|c|c|}
\hline & & B & SE & Beta \\
\hline 1 & (Constant) & 1.152 & .287 & \\
& Price & .553 & .083 & $.314^{* * * *}$ \\
Design & .146 & .085 & $.080^{*}$ \\
Size & .124 & .065 & $.088^{*}$ \\
Updatemap & .192 & .084 & $.116^{* *}$ \\
Easyuse & .306 & .072 & $.209 * * *$ \\
\hline \multicolumn{2}{|c|}{} & *** significance 0.01 ** significance 0.05 * significance 0.1 \\
\hline
\end{tabular}

a. Dependent Variable: SATISFACTION

B: Unstandardized Coefficients, SE: Std. Error, Beta: Standardized Coefficients

$\left\langle\right.$ Table 8〉 Regression results of each segment ${ }^{a}$

\begin{tabular}{|ll|c|c|c|}
\hline & & Segment 1 & Segment 2 & Segment 3 \\
\hline \multirow{2}{*}{ \# of observation } & & $\mathrm{n}=187$ & $\mathrm{n}=168$ & $\mathrm{n}=57$ \\
& Price & $0.5610^{* * *}$ & $0.3826^{* * * *}$ & $0.6596^{* *}$ \\
& Design & 0.1678 & 0.0707 & 0.2537 \\
& Update & 0.1069 & $0.2077^{* *}$ & -0.1487 \\
& Easyuse & 0.0473 & -0.1188 & $0.7098^{* * *}$ \\
& Multimedia & $0.2567^{* *}$ & $0.5660^{* * *}$ & 0.1140 \\
\hline \multirow{2}{*}{ Adjusted $\mathrm{R}^{2}$} & & 0.2963 & 0.3320 & 0.4444 \\
F & $16.6571^{* * *}$ & $17.5998^{* * *}$ & $9.9591 * * *$ \\
\hline
\end{tabular}

a. Dependent Variable: SATISFACTION

68 ASIA MARKETING JOURNAL Vol. 16 No. 03 October 2014 
size. After excluding the size from the analysis, all other hardware design attributes exhibited statistically significant influence on customer satisfaction while maintaining the fit of the regression model about the same as before. Such insignificance of the size variable is also prevalent in the regression analysis on each segment. The following regression results on each segment are obtained with the size variable excluded.

To check the differences between the regression coefficients across segments, a Chow test was performed (Chow, 1960). The Chow test result (Segments1-2: $\mathrm{F}=4.73$, segment2-3: $\mathrm{F}=7.6$, segment1-3: $\mathrm{F}=2.28, \mathrm{p}<0.05)$ indicates statistically significant differences among segments, which validates Hypothesis 3.

These results are recapitulated in the following Figure. 1, Figure. 2 and Figure. 3.

- Group 1: 45\% of the sample that showed the highest expectation level toward all service attributes; fairly interested group of telematics users

- Group 2: $41 \%$ of the sample that showed

〈Table 9〉 Regression results of each segment ${ }^{\mathrm{a}}$

\begin{tabular}{|ll|c|c|c|}
\hline & & Seg1 - Seg2 & Seg2 - Seg3 & Seg3 - Seg1 \\
\hline Coefficient & Intercept & $0.821^{* *}$ & $0.853^{* *}$ & $1.747^{* *}$ \\
& Price & $0.628^{* * *}$ & $0.508^{* * *}$ & $0.495^{* * *}$ \\
& Design & 0.181 & 0.146 & 0.121 \\
& Update & 0.086 & 0.101 & $0.156^{* *}$ \\
& Easyuse & $0.354^{* *}$ & $0.219^{* *}$ & 0.016 \\
& Multimedia & $0.194^{*}$ & $0.351^{* * *}$ & $0.376^{* * *}$ \\
\hline Adjusted $\mathrm{R}^{2}$ & & 0.349 & 0.385 & 0.324 \\
F & $25.011^{* * *}$ & $31.365^{* * *}$ & $34.924^{* * *}$ \\
\hline
\end{tabular}

a. Dependent Variable: SATISFACTION

〈Figure 1〉 Regression results (Group 1)

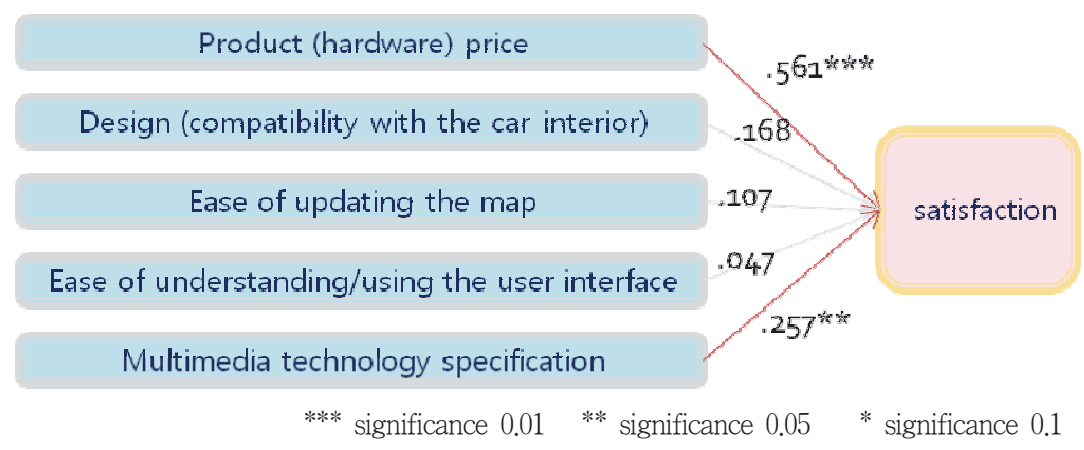


〈Figure 2〉 Regression results (Group 2)

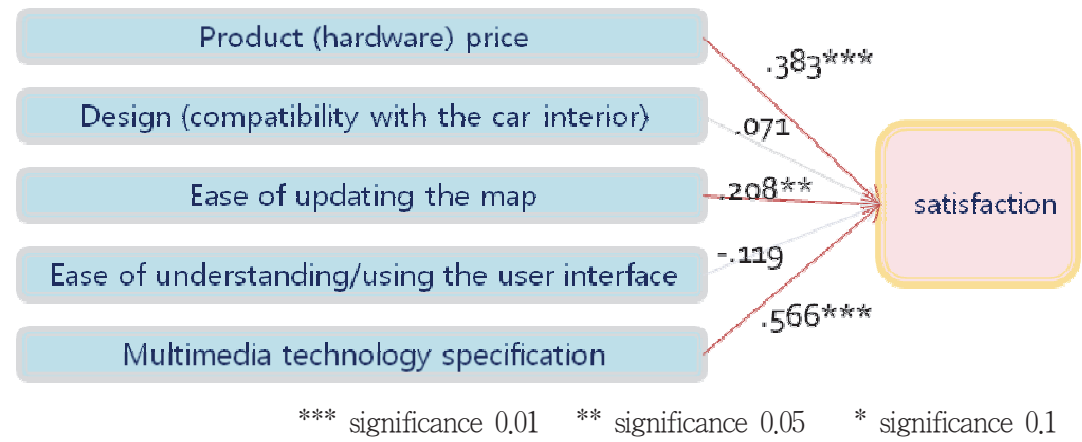

〈Figure 3〉 Regression results (Group 3)

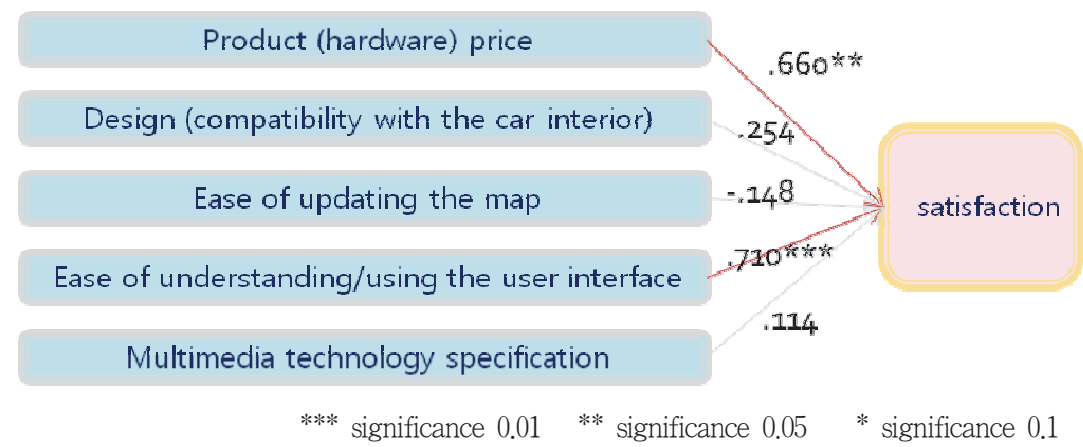

the medium expectation level overall; rel- $^{-}$ atively high expectation on safety service and less expectation on personally customized IT service

- Group 3: $14 \%$ of the sample that showed the lowest expectation level overall; relatively high expectation on the safety service and low expectation on personally customized IT service

One common significant factor in all three segments was price. According to Srinivasan et al. (1997), price is almost always an important product attribute.
By checking the regression coefficients, it was verified that product aspects that influence their satisfaction to a greater extent varied between the customer groups with different expectation over the service quality. This approach can be utilized as a method to associate the product (hardware) design with customers' service quality expectation. As can be seen from Figure 1, Figure 2 and Figure 3, the satisfaction of the group 1 is mainly influenced by the price and multimedia specification of telematics system. This implicates that the group 1 customers are more likely to put high importance on the price and the multimedia functions of the telematics 
system. In this sense, group 1 can be considered to be relatively IT-savvy since customers have high expectation on the service quality and their satisfaction is influenced much by multimedia functions. The group 2 customers showed much importance on ease of map update. The group 3 customers with the lowest satisfaction level on all the service attributes consider user-friendliness of the interface much more important than customers of other groups. Consumers with low expectations, especially in personally customizable IT service, are likely to be novices in IT products and tend to be more satisfied when they can utilize the telematics system easily.

\section{Conclusion}

As products are more closely associated with services for value enhancement, the product design strategy also needs to reflect such trend (Lenfle \& Midler, 2009). In a market characterized by products closely tied with services, a product differentiation strategy that utilizes information on the linkage between consumers' expectations on service quality and the product attributes can greatly enhance profitability.

In order to incarnate such approach to the product design task in the automotive telematics industry, a two-staged study utilizing actual customer data of the automotive telematics in- dustry was conducted. First, consumer samples are segmented based on their expectations on qualities of service attributes. For this purpose, service quality determinants of automotive telematics systems were carefully identified via interviews with industry experts. Such expectation-based segmentation is more efficient than segmentation based on demographic variables in terms of relevance to the actual needs of customers.

Second, after identifying the characteristics of segmented groups, systematic differences among segments with respect to the pattern of preferences among the product attributes are revealed. Results from this study can provide a pricing and the product quality design guidance to the telematics system supplier. The result of this two-stage approach to the product design is that, through consumer segmentation based on quality expectation, various patterns of emphases on service attributes are matched with the product design configurations.

On the other hand, the hypothesis that consumers' quality expectation pattern will vary according to different relative importance on service quality attributes was not supported by the data. As the automotive telematics market matures and consumers accumulate usage experiences, we might come across a much more significant correlation between service quality expectation and importance distribution patterns. Advices to telematics designers at IT-Car can be summarized as follows. For the group 1 customers, all-around high quality services with 
emphasis on strong multimedia functionalities and highly flexible and customizable features should be provided. For the group 2 customers, the strengths of the system should be placed on safety and map updates. For the group 3 customers, telematics systems that are easy to use, that come with preset functionalities that require minimal efforts by the user, along with high level of safety functionalities need to be provided.

There are a number of limitations and much need for further studies. The survey collection methodology via mass e-mail with current customers of telematics cannot incorporate perspectives of non-users of telematics systems. Also, as pointed out in the main body, it is more desirable to include balanced portfolio of respondents in terms of demographic variables in which case one might be able to reveal control effects of such variables.

〈Received August 28. 2013〉

〈Revised July 7. 2014〉

〈Accepted October 28. 2014〉

\section{References}

Agarwal, J., Malhotra, N.K. and Bolton, R.N. (2010), "A cross-national and cross-cultural approach to global market segmentation: an application using consumers' perceived service quality," Journal of International
Marketing, Vol. 18 No. 3, pp. 18-40.

Arabie, P. and Hubert, I. (1994), "Cluster analysis in marketing research," in Bagozzi, R.P. (Ed), Advanced Methods in Marketing Research, Blackwell, Cambridge, MA.

Athanassopoulos, A.D. (2000), "Customer satisfaction cues to support market segmentation and explain switching behavior," Journal of Business Research, Vol. 47 No. 3, pp. $191-207$.

Bernués, A., Olaizolab, A. and Corcoran, K. (2003), "Extrinsic attributes of red meat as indicators of quality in Europe: an application for market segmentation," Food Quality and Preference, Vol. 14 No. 4, pp. 265-76.

Bloch, P.H. (1995), "Seeking the ideal form: product design and consumer response," The Journal of Marketing, Vol. 59 No.3, pp. 16-29.

Carman, J.M. (1990), “Consumer perceptions of service quality: an assessment of the SERVQUAL dimensions," Journal of Retailing, Vol. 66 No. 1, pp. 33-55.

Chen, H. and Chen, S. (2009), “The empirical study of automotive telematics acceptance in Taiwan: comparing three Technology Acceptance Models," International Journal of Mobile Communications, Vol. 7 No. 1, pp. 50-65.

Chow, G.C. (1960), "Test of equality between sets of coefficients in two linear regressions," Econometrica, Vol. 28 No. 3, pp. 591-605. 
Dean, A.M. (2004), "Rethinking customer expectations of service quality: are call centers different?," The Journal of Services Marketing, Vol. 18 No. 1, pp. 60-77.

Diaz-Martin, A.M., Iglesias, V., Vazquez, R. and Ruiz, A.V. (2000), "The use of quality expectations to segment a service market," Journal of Services Marketing, Vol. 14 No. 2, pp. 132-46.

Dimitriadis, S. (2011), “Customers' relationship expectations and costs as segmentation variables: preliminary evidence from banking," Journal of Services Marketing, Vol. 25 No. 4, pp. 294-308.

Driver, C. and Johnston, R. (2001), "Understanding service customers: the value of hard and soft attributes," Journal of Service Research, Vol. 4 No.2, pp. 130-9.

Edvardsson, B., Gustafsson, A., Johnson, M.D. and Sanden, B. (2000), New service development and innovation in the new economy, Studentlitteratur, Lund, Sweden.

Furrer, O., Liu, B.S. and Sudharshan, D. (2000), "The relationships between culture and service quality perceptions - basis for crosscultural market segmentation and resource allocation," Journal of Service Research, Vol. 2 No. 4, pp. 355-71.

Fornengo, G. (1988), "Manufacturing networks: telematics in the automotive industry" in Antonelli, C. (Ed), New information technology and industrial change: the Italian case, Springer Netherlands, Brussels and
Luxembourg.

Frank, R.E., Massy, W. and Wind, Y. (1972), Market Segmentation, Prentice-Hall, Englewood Cliffs, NJ.

Gagliano, K.B. and Hathcote, J. (1994), "Customer expectations and perceptions of service quality in retail apparel specialty stores," Journal of Service Marketing, Vol. 8 No. 1, pp. 60-9.

Global Industry Analysts (2012), Commercial vehicle telematics.

Green, P.E., Carroll, J.D. and Goldberg, S.M. (1981), “A general approach to product design optimization via conjoint analysis," The Journal of Marketing, Vol. 45 No. 3, pp. 17-37.

Gronroos, C. (1984), “A service quality model and its marketing implications," European Journal of Marketing, Vol. 18 No.4, pp. $36-44$.

Haley, R.I. (1968), "Benefit segmentation: a decision-oriented research tool," Journal of Marketing, Vol. 32 No.3, pp. 30-5.

J.D. Power and Associates (2012), U.S. navigation usage and satisfaction study.

Lenfle, S. and Midler, C. (2003), "Innovation in automotive telematics services: characteristics of the field and management principles," International Journal of Automotive Technology and Management, Vol. 3 No 1, pp. $144-59$.

Lenfle, S. and Midler, C. (2009), "The launch of innovative product-related services: lessons 
from automotive telematics," Research Policy, Vol. 38 No. 1, pp. 156-69.

Liu, Y., Kiang, M. and Brusco, M. (2012), “A unified framework for market segmentation and its applications," Expert Systems with Applications, Vol. 39 No. 11, pp. 10292302.

Loiacono, E., Watson, R. and Goodhue, D. (2002), "WEBQUAL: a measure of website quality" in Evans, K. and Scheer, L. (Ed), 2002 Marketing Educators' Conference: Marketing Theory and Applications, American Marketing Association, Chicago, IL, pp. 432-8

Loker, L.E. and Perdue, R. (1992), "A benefitbased segmentation of nonresident summer travel market," Journal of Travel Research, Vol. 31 No. 1, pp. 30-5.

Okazaki, S. (2006), "What do we know about mobile Internet adopters? A cluster analysis," Information and Management, Vol. 43 No. 2, pp. 127-41.

Otim, S. and Grover, V. (2006), "An empirical study on Web-based services and customer loyalty," European Journal of Information Systems, Vol. 15 No. 6, pp. 527-41.

Moriarty, R.T. and Reibstein, D.J. (1986), "Benefit segmentation in industrial markets," Journal of Business Research, Vol. 14 No. 6, pp. 463-86.

Mitchell, V.W. (1994), "How to identify psychographic segments: part 1," Marketing Intelligence and Planning, Vol. 12 No. 7, pp. 4-10.
Parasuraman, A., Zeithaml, V.A. and Berry, L.L. (1985), "A conceptual model of service quality and its implications for future research," The Journal of Marketing, Vol. 49 No. 4, pp. 41-50.

Parasuraman, A., Zeithaml, V.A. and Berry, L.L. (1988), "SERVQUAL: A multipleitem scale for measuring service quality," Journal of Retailing, Vol. 64 No. 1, pp. 12-40.

Parasuraman, A., Zeithaml, V.A. and Arvind, M. (2005), "E-S-QUAL: A multiple-item scale for assessing electronic service quality," Journal of Service Research, Vol. 7 No. 3, pp. 213-33.

Pitt, L., Morris, M.H. and Oosthuizen, P. (1996), "Expectations of service quality as an industrial market segmentation variable," The Service Industries Journal, Vol. 16 No. 1, pp. 1-9.

Rao, C.P. and Wang, Z. (1995), "Evaluating alternative segmentation strategies in standard industrial markets," European Journal of Marketing, Vol. 29 No. 2, pp. 58-75.

Rust, R.T. and Lemon, K.N. (2001), "E-service and the consumer," International Journal of Electronic Commerce, Vol. 5 No. 3, pp. 85-101.

Seltsikas, P. and O'Keefe, R.M. (2010), "Expectations and outcomes in electronic identity management: the role of trust and public value," European Journal of Information Systems, Vol. 19 No. 1, pp. 93-103. 
Srinivasan, V., Lovejoy, W.S. and Beach, D. (1997), "Integrated product design for marketability and manufacturing," Journal of Marketing Research, Vol. 34 No. 1, pp. 154-63.

Thompson, A.M. and Kaminski, P.F. (1993), "Psychographic and lifestyle antecedents of service quality expectations: a segmentation approach," Journal of Service Marketing, Vol. 7 No. 4, pp. 53-61.

Verbeke, W., Vermeir, I. and Brunsø, K. (2007), "Consumer evaluation of fish quality as basis for fish market segmentation," Food Quality and Preference, Vol. 18 No. 4, pp. 651-61.

Webster, C. (1989), "Can consumers be segmented on the basis of their service quality expectations," Journal of Service Marketing, Vol. 3 No. 2, pp. 35-53.

Weinstein, A. (1994), Market segmentation: using demographics, psychographics and other niche marketing techniques to predict and model customer behavior, Probus, Chicago. Wikipedia (2013), "Telematics," available at: http://en.wikipedia.org/wiki/Telematics (accessed 22 February 2013).

Williams, A. (2007), "Product service systems in the automobile industry: contribution to system innovation?," Journal of Cleaner Production, Vol. 15 No. 11, pp. 1093-103.
Wind, Y. (1978), "Issues and advances in segmentation research," Journal of Marketing Research, Vol. 15 No. 3, pp. 317-37.

Woo, K. (1998) "Using quality perceptions to segment customers in services," Marketing Intelligence and Planning, Vol. 16 No. 7, pp. 418-24.

Wu, S. (2006), "A comparison of the behavior of different customer clusters towards Internet bookstores," Information and $\mathrm{Ma}^{-}$ nagement, Vol. 43 No. 8, pp. 986-1001.

Yang, Z. and Fang, X. (2000), "Online service quality dimensions and their relationships with satisfaction: a content analysis of customer reviews of securities brokerage services," International Journal of Service Industry Management, Vol. 15 No. 3, pp. 302-26.

Yoo, B. and Donthu, N. (2001), "Developing a scale to measure the perceived quality of an Internet shopping site (SITEQUAL)," Quarterly Journal of Electronic Commerce, Vol. 2 No. 1, pp. 31-47.

Zeithaml, V.A., Berry, L.L. and Parasuraman, A. (1993), "The nature and determinants of customer expectations of service," Journal of the Academy of Marketing Science, Vol. 21 No. 1, pp. 1-12. 